\title{
Quatro poemas de Philip Larkin
}

\author{
Alípio Correia de Franca Neto
}

\section{This be the verse}

They fuck you up, your mum and dad.

They may not mean to, but they do.

They fill you with the faults they had

And add some extra, just for you.

But they were fucked up in their turn

By fools in old-style hats and coats,

Who half the time were soppy-stern

And half at one another's throats.

Man hands on misery to man.

It deepens like a coastal shelf.

Get out as early as you can.

And don't have any kids yourself. 
Alípio Correia de Franca Neto. Quatro poemas de Philip Larkin

\section{Seja este o verso}

Eles te fodem, teus queridos pais.

É sem querer, mas a verdade é esta:

Te enchem das culpas que tiveram mais

E dão, só pra você, uma dose extra.

Mas eles se foderam com uns néscios

De paletós e de chapéus à antiga,

Durante o dia, piegas e perversos,

De noite, se esganando numa briga.

Legamos dor aos nossos semelhantes.

Como um recife, ela se crava fundo.

Por isso, saia dessa o quanto antes

E nunca ponha filhos neste mundo. 


\section{Vers de Société}

My wife and I have asked a crowd of craps

To come and waste their time and ours: perhaps

You'd care to join us? In a pig's arse, friend.

Day comes to an end.

The gas fire breathes, the trees are darkly swayed.

And so Dear Warlock-Williams: I'm afraid-

Funny how hard it is to be alone.

I could spend half my evenings, if I wanted,

Holding a glass of washing sherry, canted

Over to catch the drivel of some bitch

Who's read nothing but Which;

Just think of all the spare time that has flown

Straight into nothingness by being filled

With forks and faces, rather than repaid

Under a lamp, hearing the noise of wind,

And looking out to see the moon thinned

To an air-sharpened blade.

A life, and yet how sternly it's instilled

All solitude is selfish. No one now

Believes the hermit with his gown and dish

Talking to God (who's gone too); the big wish

Is to have people nice to you, which means

Doing it back somehow.

Virtue is social. Are, then, these routines 
Alípio Correia de Franca Neto. Quatro poemas de Philip Larkin

Playing at goodness, like going to the church?

Something that bores us, something we don't do well

(Asking that ass about his fool research)

But try to feel, because, however crudely,

It shows us what should be?

Too subtle, that. Too decent, too. Oh hell,

Only the young can be alone freely.

The time is shorter now for company,

And sitting by a lamp more often brings

Not peace, but other things.

Beyond the light stand failure and remorse

Whispering Dear Warlock-Williams: Why, of course - 


\section{Vers de Société}

Minha esposa e eu chamamos um bando de merdas

Pra jogar conversa fora: daria o prazer da

Sua presença? Vai tomar no cu, cara. O dia

Chega ao seu fim. Sombrias

Balançam as árvores, chia o aquecimento.

Por isso, Meu caro Warlock-Williams, eu lamento...

Engraçado como é difícil ficar só. Eu,

Quando queria, passava as noites com um copo

De xerez intragável, inclinando o corpo

Pra ouvir besteiras de alguma bisca boçal

Que só sabe ler Qual;

Pense só naquele tempo livre que deu

Em nada, cheio de garfos, rostos, sem senti-lo

Recompensado sob a luz da lamparina,

Ouvindo o vento, vendo fora a lua flutuar,

Já reduzida até uma lâmina que o ar

Foi deixando mais fina.

Uma vida, e com que seriedade se instila o

A solidão é sempre egoísta. Hoje ninguém

Crê no ermitão de burel e tigela, que ora

A Deus (que foi-se junto); o grande voto agora

É ter gente gentil com você, o que implica

Portar-se assim também.

A virtude é social. Essas rotinas ficam 
Alípio Correia de Franca Neto. Quatro poemas de Philip Larkin

Brincando de bondade, assim como ir à missa?

São algo que chateia, ou não fazemos bem

(Como indagar ao asno sobre sua pesquisa)

Mas se tenta estimar, pois diz, mesmo imperfeito,

O que seria direito?

Sutil demais, essa. Conveniente também.

Diabo! Só os jovens ficam sós com alegria.

O tempo está mais curto para companhia

E sentar junto à lamparina às vezes traz

Várias coisas, não paz.

Além da luz, o fracasso e o remorso param,

A sussurrar, Caro Warlock-Williams: Mas é claro. 


\section{Here}

Swerving east, from rich industrial shadows

And traffic all night north; swerving through fields

Too thin and thistled to be called meadows,

And now and then a harsh-named halt, that shields

Workmen at dawn; swerving to solitude

Of skies and scarecrows, haystacks, hares and pheasants,

And the widening river's slow presence,

The piled gold clouds, the shining gull-marked mud,

Gathers to the surprise of a large town:

Here domes and statues, spires and cranes cluster

Beside grain-scattered streets, barge-crowded water,

And residents from raw estates, brought down

The dead straight miles by stealing flat-faced trolleys, Push through plate-glass swing doors to their desires Cheap suits, red kitchen-ware, sharp shoes, iced lollies, Electric mixers, toasters, washers, driers -

A cut-price crowd, urban yet simple, dwelling Where only salesmen and relations come

Within a terminate and fishy-smelling

Pastoral of ships up streets, the slave museum, Tattoo-shops, consulates, grim head-scarfed wives;

And out beyond its mortgaged half-built edges Fast-shadowed wheat-fields, running high as hedges, Isolate villages, where removed lives 
Alípio Correia de Franca Neto. Quatro poemas de Philip Larkin

Loneliness clarifies. Here silence stands

Like heat. Here leaves unnoticed thicken,

Hidden weeds flower, neglected waters quicken,

Luminously-peopled air ascends;

And past the poppies bluish neutral distance

Ends the land suddenly beyond a beach

Of shapes and shingle. Here is unfenced existence:

Facing the sun, untalkative, out of reach. 


\section{Aqui}

Virar pro Leste, saindo de soberbas sombras industriais, Trânsito ao norte noite adentro, pelos campos, cujo cardo

E a relva rala impedem que os chamemos prados, com eventuais

Paragens com um nome áspero, abrigos que resguardam

Trabalhadores de manhã; virar pra solidão remota

De céus e de espantalhos, lebres, feno em feixes e faisões,

Com a presença lenta de um rio se alastrando, com montões

De nuvens de ouro, o barro ao sol trazendo marcas de gaivota -

Virar assim culmina na surpresa da grande cidade:

Aqui, estátuas, domos, torres e guindastes fazem par com

Ruas salpicadas de grãos e com águas cheias de barcos,

$E$ a gente das herdades toscas, que viajou por uma estrada

Reta e sem fim, num trolley a furto e de focinho chato,

Empurra a porta envidraçada rumo a tudo o que ela queira:

Os "bicos finos", tachos rubros, picolés, terno barato,

Ou secadora, lavadora, batedeira e torradeira -

É a "turba do desconto", urbana embora simples, e que vem de Lugares aonde apenas vendedores e parentes vão,

Partes da pastoral de barcos reduzida, que recende A peixe rua acima; e partes do museu da escravidão, Dos consulados, lojas de tatuagem, dos duros semblantes De mulheres com lenço na cabeça. E além de suas fronteiras Por acabar, hipotecadas, trigais de sombras ligeiras,

Altos como a sebe, isolam a aldeia, com vidas distantes 
Alípio Correia de Franca Neto. Quatro poemas de Philip Larkin

Que a solidão ilumina. Aqui, é o silêncio que perdura

Como calor. Aqui, folhas se espessam sem que ninguém veja,

Águas ignoradas se aceleram, a erva oculta viceja

E o ar, povoado de revérberos, eleva-se na altura;

Finda a distância neutra e azulada das papoulas, e a areia

De seixos e formas, a terra se interrompe, num relance.

Aqui uma espécie de existência a que limite algum refreia:

Voltada como está pro sol, lacônica, fora do alcance. 


\section{Aubade}

I work all day, and get half-drunk at night.

Waking at four to soundless dark, I stare.

In time the curtain-edges will grow light.

Till then I see what's really always there:

Unresting death, a whole day nearer now,

Making all thought impossible but how

And where and when I shall myself die.

Arid interrogation: yet the dread

Of dying, and being dead,

Flashes afresh to hold and horrify.

The mind blanks at the glare. Not in remorse

- The good not done, the love not given, time

Torn off unused - nor wretchedly because

An only life can take so long to climb

Clear of its wrong beginnings, and may never;

But at the total emptiness for ever,

The sure extinction that we travel to

And shall be lost in always. Not to be here,

Not to be anywhere,

And soon; nothing more terrible, nothing more true.

This is a special way of being afraid

No trick dispels. Religion used to try,

That vast moth-eaten musical brocade

Created to pretend we never die,

And specious stuff that says No rational being

Can fear a thing it will not feel, not seeing 
That this is what we fear - no sight, no sound, No touch or taste or smell, nothing to think with,

Nothing to love or link with,

The anaesthetic from which none come round.

And so it stays just on the edge of vision,

A small unfocused blur, a standing chill

That slows each impulse down to indecision.

Most things may never happen: this one will,

And realisation of it rages out

In furnace-fear when we are caught without

People or drink. Courage is no good:

It means not scaring others. Being brave

Lets no one off the grave.

Death is no different whined at than withstood.

Slowly light strengthens, and the room takes shape.

It stands plain as a wardrobe, what we know,

Have always known, know that we can't escape,

Yet can't accept. One side will have to go.

Meanwhile telephones crouch, getting ready to ring

In locked-up offices, and all the uncaring

Intricate rented world begins to rouse.

The sky is white as clay, with no sun.

Work has to be done.

Postmen like doctors go from house to house. 


\section{Aubade}

Trabalho o dia inteiro; à noite, eu encho a cara.

Olho o negror sem som, me levantando às quatro.

Em tempo, a borda da cortina vai estar clara.

Até lá, vejo aquilo que está ali, de fato:

A morte infatigável, um dia mais perto,

Tornando inviável todo pensamento, exceto

O de onde, como e quando a minha vai chegar.

Uma pergunta estéril: mas o horror que eu sinto

Quanto a morrer e ser extinto

Luz outra vez, para se impor e apavorar.

A mente apaga-se ao clarão. Não é o remorso

- O bem que não se faz, o amor que não se vive,

O tempo arrancado sem uso -, ou a dor de nossa

Única vida custar tanto a se erguer, livre

De origens torpes, ou jamais se erguer. É vermos

Esse vazio absoluto e sem um termo,

Aquela inevitável extinção final

Aonde vamos nos perder pra sempre. Não estar

Aqui, não estar noutro lugar,

E em breve: nada mais terrível e real.

Esse é um tipo especial de medo, a que trapaça

Nenhuma anula. A religião se empenhou nisto,

Vasto brocado musical roído de traça,

Criado pra fingir que não se morre, e ditos

Especiosos, como "nenhum ser consciente 
Alípio Correia de Franca Neto. Quatro poemas de Philip Larkin

Pode ter medo daquilo que não se sente",

Sem ver que este é o medo: não ver, ouvir, tocar,

Cheirar, ter gosto, nada com que refletir,

Ou com que amar, ou a que se unir,

A anestesia da qual ninguém pode voltar.

E permanece assim, na fímbria da visão,

A mancha desfocada, o calafrio que só retrai,

Contínuo, cada impulso, e o torna indecisão.

Coisas talvez não vão se dar - mas esta vai,

E a nossa consciência entra em agonia, entregue a

Horror-fornalha, toda vez que ela nos pega

Sem bebida ou companhia. Coragem não conta:

Visa não assustar os outros. A bravura

Não vai poupar da sepultura.

A morte é a mesma, se você a teme ou afronta.

A luz aumenta aos poucos, toma forma o quarto.

Lá está, tão claro quanto o armário, o que se sabe

E soube sempre, aquilo a que ninguém é apto

A fugir, e não se aceita. A um dos lados cabe

Ceder. Em salas por abrir, nesse entremeio,

Vai soar, de cócoras, o telefone, e o alheio,

Complexo mundo de aluguel vai despertar.

Sem sol e branco como argila é o firmamento.

Há trabalho para ser feito.

Carteiros e médicos vão de lar em lar. 